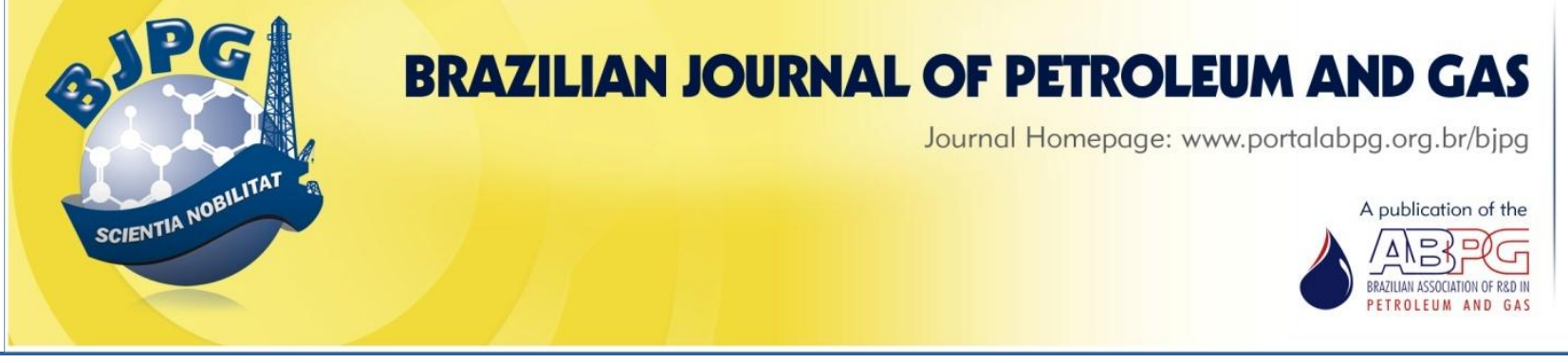

\title{
LONG-RANGE PLANNING FOR THE BRAZILIAN PETROCHEMICAL INDUSTRY USING MIXED-INTEGER PROGRAMMING
}

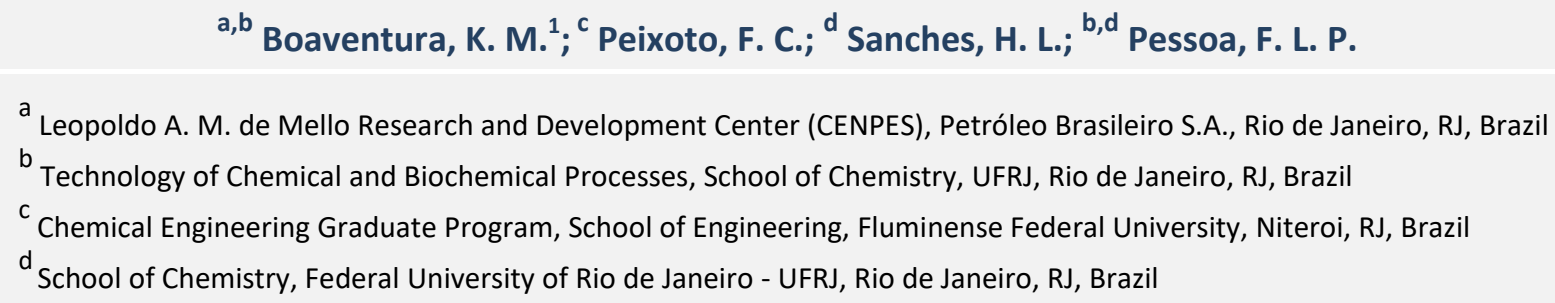

Received: 30.08.2017 / Revised: 10.11.2017 / Accepted: 16.11.2017 / Published on line: 21.12.2017

\begin{abstract}
A mixed-integer multiperiod model is used to propose a long-range planning for the Brazilian petrochemical industry. The specific aims of this work are to present a model to select the petrochemical processes capable of increasing over the next 20 years and carry out a sensitivity analysis of this selection if there are changes in demands for products or in the purchase prices of chemicals. The optimization model seeks to minimize the cost and the constraints related to demand, supply, and plant capacities in the petrochemical industry. The long-range planning was suggested for six scenarios, which differ according to the investment constraints, demands for products, and chemicals purchase prices imposed. Among the 295 processes considered, 26 were selected for investment in new process units through the optimization procedure in all scenarios, such as the processes for the production of polyurethane and acrylic fibers. These results are consistent with previous studies of investment assessment of the Brazilian petrochemical industry.
\end{abstract}

\section{KEYWORDS}

long-range planning; mixed-integer programming; multiperiod optimization model; petrochemical industry; investment assessment

\footnotetext{
${ }^{1}$ To whom all correspondence should be addressed. Address: Leopoldo A. M. de Mello Research and Development Center (CENPES), PETROBRAS - Petróleo Brasileiro S.A, 950 Avenida Horácio Macedo, Rio de Janeiro, RJ, Brazil. ZIP Code: 21941-915 | Telephone: +55 2121624324 |e-mail: kboaventura@petrobras.com.br doi:10.5419/bjpg2017-0019
} 


\section{INTRODUCTION}

The petrochemical industry of a country can be viewed as a network in which raw materials and other chemicals are transformed into petrochemical products through chemical processes. The petroleum industry provides the basic raw materials to the petrochemical industry mainly natural gas and naphtha - and some of the intermediate products used in petrochemical processes, such as ethylene, benzene, and toluene. Also, many other chemicals are necessary to the production of final petrochemical products such as plastics, resins, fibers, elastomers, and rubbers.
Figure 1 illustrates a simplified version of the petrochemical network studied by Al-Sharrah et al. (2001), where it is seen that different processes can be used to obtain one product. For example, acetic acid can be produced from different processes using methanol, acetaldehyde, or $n$ butane. Also, different processes may compete for the same raw material. For instance, benzene can be used to produce phenol, cumene, and ethylbenzene. By varying raw materials and production processes, one can imagine many different petrochemical networks, one of them being the optimal one.

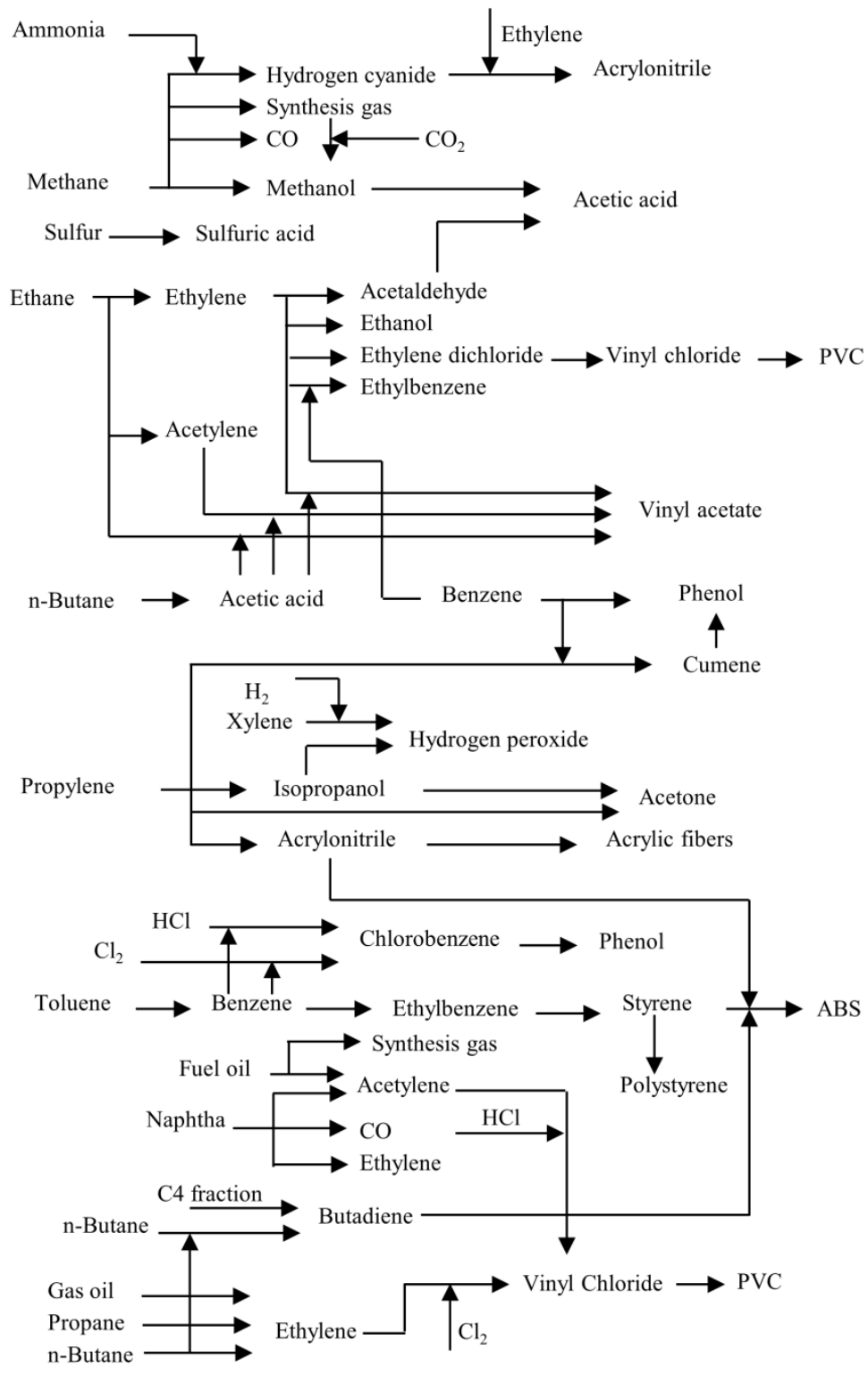

Figure 1. Simplified version of the network studied by Al-Sharrah et al. (2001). 
Therefore, mathematical models can be used to support decisions on petrochemical industry investment, since they enable the study of the impact of different economic scenarios on the petrochemical network. By optimizing the objective function defined in the model, one can decide which processes and raw materials will constitute the optimal network.

Indeed, mathematical models have been used as tools for investment assessment, new technologies evaluation, and sensitivity analysis of the network structure when supplies, demands, and costs change. Rudd et al. (1981) developed a linear monoperiod model which was used to propose a long-range planning of the United States petrochemical industry. The model consists of a cost function to be minimized considering the purchase cost of chemicals, the total process production cost (which includes raw material costs, utilities costs, labor-related costs and investmentrelated costs) and a correction term for surplus chemicals; the excess of production.

Jiménez et al. (1982) adapted the model developed by Rudd et al. (1981) for the Mexican petrochemical industry, in which chemical imports are appreciable and demands are lower than those in the United States. The authors presented a mixed-integer model of the petrochemical industry and identified that the investing in new plants to produce some chemicals is more advantageous economically than importing them. The optimization problem minimizes a cost function which considers cost of feedstock, operating cost of process, and import cost. The Mexican petrochemical industry was also studied by Toledo et al. (2010), who presented an integrated model of an industry that included petroleum refining processes, basic chemicals production, and petrochemicals production.

Al-Fadli et al. (1988) presented a linear network flow model for planning the Saudi Arabia petrochemical industry. According to the authors, the solution to the network flow model is faster than the solution offered through linear programming; consequently, there are advantages in defining alternative models when solving largedimension linear problems.

The long-range planning of the Kuwait petrochemical industry has been proposed through a number of different models. Al-Sharrah et al.
(2001) presented a mixed-integer linear programming model with two objective functions: one representing the final added value of chemicals (which is maximized) and one representing the environmental risk (which is minimized). Al-Sharrah et al. (2002) included a new set of constraints in the model presented by AlSharrah et al. (2001), to select strategic processes for which new units should be built, with the goal of providing sustainability and economic stability to the company. Al-Sharrah et al. (2003) presented long- and short-range forecasting models to predict future oil and chemical prices. These forecasting models were applied to the analysis of the Kuwait petrochemical industry planning (Al-Sharrah et al., 2001). Al-Sharrah et al. (2006) modified the model presented by Al-Sharrah et al. (2001) aiming to plan the petrochemical industry of Kuwait by maximizing its profits and minimizing risks of plant accidents.

The planning for the petrochemical industry in Brazil has also been the subject of some publications. Although the demand for chemicals in Brazil has grown in the last years, investment in the chemical industry has not followed this trend. Before 2007, the trade balance of the chemical industry was relatively stable, with a deficit between US\$ 6 billion and US\$ 9 billion (Bain \& Company, Inc. and Gas Energy, 2014). In 2007, this deficit started to increase, reaching approximately US\$ 26.5 billion in 2011 (ABIQUIM, 2012), US\$ 28 billion in 2012, and US\$ 32 billion in 2013 (Bain \& Company, Inc. and Gas Energy, 2014). Aiming to reduce the deficit in the chemical sector, the Brazilian Development Bank (BNDES), which is the main financial support instrument in Brazil for investments in all economic sectors, coordinated a study held by Bain \& Company, Inc. and Gas Energy (2014) to identify opportunities for diversification of the Brazilian chemical industry and to contribute to the design of an industrial policy for the sector. In this study, Bain \& Company, Inc. and Gas Energy (2014) detail investment opportunities for 21 primary focus segments, which are responsible for $72 \%$ of the total deficit of the chemical industry and which include products with high added values. The work presented by Bain \& Company, Inc. and Gas Energy (2014) is based on projected market, analysis of financial information, and interviews with industry participants. 
Loução Jr. (2016) applied the linear monoperiod model developed by Rudd et al. (1981) to the current Brazilian petrochemical industry, which comprises 60 chemicals and 86 processes, to find out which network structures minimize its total cost. Different scenarios were evaluated to study the impact of raw materials and the cost of the electrical energy. The author found that the total cost of the Brazilian petrochemical network is very sensitive to the naphtha price and to the cost of the electrical energy.

In the present work, a mixed-integer multiperiod model for the Brazilian petrochemical industry is proposed considering its long-range planning, that is, to indicate investment in new process units and to assess the sensitivity of its total cost to changes in chemicals demands and prices. The petrochemical network applied in the present work comprises a large number of possible processes (295) and chemicals (203), not being restricted to the current Brazilian petrochemical industry, this choice allows that different products and processes can be selected for new investment. The optimal petrochemical network is obtained through the total cost minimization over a given period.

\section{MIXED-INTEGER MULTIPERIOD MODEL OF THE PETROCHEMICAL INDUSTRY}

The petrochemical industry model presented in this work consists of a network of NP processes and NC chemicals, including raw materials, intermediate and final products; the industry evolves over the discrete time $t$, for $N T$ periods. The total cost of the petrochemical industry over the $N T$ periods (the objective function) is described by Equation (1), where $I C_{j, t}$ and $O C_{j, t}$ are the investment and operational costs of process $j$ at time $t$, respectively; $P_{i, t}$ is the amount of product $i$ purchased at time $t$, with $p p_{i, t}$ being its respective purchase price.

$I=\left\{\right.$ chemical $_{1}$, chemical $_{2}, \ldots$, chemical $\left._{N C}\right\}$

$J=\left\{\right.$ process $_{1}$, process $_{2}, \ldots$, process $\left._{N P}\right\}$

$T=$ period $_{1}, \operatorname{period}_{2}, \ldots$, period $\left._{N T}\right\}$ $\min Z=\sum_{t \in T} \sum_{j \in J} I C_{j, t}+$

$+\sum_{t \in T} \sum_{j \in J} O C_{j, t}+\sum_{t \in T} \sum_{i \in I} P_{i, t} p p_{i, t}$

The objective function, Equation (1), is subject to constraints defined in Equations (2), (3) and (4). In Equation (2), the left-hand side represents the market service of chemical $i$ at time $t$. The product availability is defined as the purchase of product $i$ at time $t, P_{i, t}$, plus the total production of product $i$ at time $t$, which is equal to $Q T_{j, t} a_{i, j}\left(Q T_{j, t}\right.$ is the total capacity of process $j$ at time $t$ and $a_{i, j}$ is the coefficient of production or consumption of product $i$ in process $j$ ). The product availability of chemical $i$ at time $t$ must be higher than its demand $D_{i, t}$ at time $t$.

$P_{i, t}+\sum_{j \in J} Q T_{j, t} a_{i, j} \geq D_{i, t} \quad \forall(i, t)$

$P_{i, t} \leq S_{i, t} \forall(i, t)$

$\operatorname{Qmin}_{j} y_{j, t} \leq Q_{j, t} \leq \operatorname{Qmax}_{j} y_{j, t} \forall(j, t)$

Equation (3) means that the purchase of product $i$ at time $t, P_{i, t}$, must be less than the supply of $i$ at time $t, S_{i, t}$, which is offered from outside the petrochemical network under analysis. In Equation (4), it is stated that the capacity of process $j$ added at time $t, Q_{j, t}$ (that is, the increase in capacity of process $j$ predicted by the model solution) is greater than a lower bound $Q \min _{j}$ and less than an upper bound $Q \max _{j}$. The adoption of a constraint involving $\mathrm{Qmin}_{j}$ prevents $Q_{j, t}$ from becoming too low, which would be physically and economically inconvenient. The integer variable $y_{j, t}$ indicates investment in process $j$ at time $t$ : it has the value 0 if no investment is made and 1 if new investment in process $j$ is made.

The total capacity of process $j$ at time $t\left(Q T_{j, t}\right)$ in Equation (5) is the sum of the new capacity of process $j$ at time $t\left(Q_{j, t}\right)$ and the total capacity of process $j$ at time $t-1\left(Q T_{j, t-1}\right) . Q_{j, t}$ represents the increase in the capacity of process $j$ predicted by the model solution. Investment and operational costs of process $j$ at time $t, I C_{j, t}$ and $O C_{j, t}$, are calculated by Equations (6) and (7), respectively. The investment cost is defined by the product of its unit value $\left(i c_{j, t}\right)$ and the new capacity of process $j$ in time $t\left(Q_{j, t}\right)$, as shown in Equation (6). The operational cost $\left(O C_{j, t}\right)$ is calculated with Equation (7) and is the product of the unit value $\left(o c_{j, t}\right)$ and the total capacity of process $j$ in time $t\left(Q T_{j, t}\right)$. 


$$
\begin{aligned}
& Q T_{j, t}=Q_{j, t}+Q T_{j, t-1} \forall(j, t) \\
& I C_{j, t}=Q_{j, t} i c_{j, t} \forall(j, t) \\
& O C_{j, t}=Q T_{j, t} O c_{j, t} \forall(j, t)
\end{aligned}
$$

The mathematical model includes other constraints: although a product can be obtained through different processes, the model can indicate only one process each period to produce a product (Equations (8) and (9)). This procedure allows the choice of the best process for producing a certain chemical according to the established scenario. Also, the model can only choose a new process for producing a main product each five years (it is considered that it is not reasonable to invest in a new plant for the production of a chemical in less than five years after the last investment), as established in Equations (10) and (11).

The process parameter of product $i$ in process $j$, $p c_{i, j}$, indicates if the product $i$ is the main product of process $j$. The value of $p c_{i, j}$ is 1 if product $i$ is the main product of process $j$ and 0 for all other processes. Each process has only one main product. Equation (8) states that the variable ProcCont $_{i, t}$, is the control of the processes that produce product $i$ in time $t$; it is defined by the sum of $p c_{i, j} y_{j, t}\left(p c_{i, j}\right.$ is the process parameter of product $i$ in process $j$ and $y_{j, t}$ is an integer variable that indicates investment in process $j$ at time $t$ ). The constraint in Equation (9) establishes that ProcCont $_{i, t}$, the control of the processes that produce product $i$ in time $t$, has to be less or equal to 1 , assuring that only one process can be selected each period $t$ to produce a product $i$.

$$
\begin{aligned}
& \operatorname{ProcCont}_{i, t}=\sum_{j \in J} p c_{i, j} y_{j, t} \forall(i, t) \\
& \text { ProcCont }_{i, t} \leq 1 \forall(i, t)
\end{aligned}
$$

ProdCont $_{i, t}$ that is, the control of the investment on a new process to produce product $i$ in time $t$, is the sum of the control of the processes that produce product $i$ in time $t$, ProcCont $t_{i, t}$ in the five prior consecutive years (Equation (10)). In Equation (11), ProdCont ${ }_{i, t}$ has to be less or equal than 1 , stating that the model can only choose a new process for producing a main product each five years.

$$
\text { ProdCont }_{i, t}=\text { ProcCont }_{i, t-4}+
$$

$$
\begin{aligned}
& + \text { ProcCont }_{i, t-3}+\text { ProcCont }_{i, t-2}+ \\
& + \text { ProcCont }_{i, t-1}+\text { ProcCont }_{i, t} \quad \forall(i, t) \\
& \text { ProdCont }_{i, t} \leq 1 \quad \forall(i, t)
\end{aligned}
$$

\section{PROBLEM STATEMENT}

The model of the Brazilian petrochemical industry is comprised of $N C=203$ chemicals and $N P$ $=295$ processes, based on data presented by Rudd et al. (1981). The petrochemical network may include products that are produced through different chemical processes. The data presented by Rudd et al. (1981) were not updated as the main aim of the present work is to validate the proposed model. Once it is validated, different products and new technologies can be included, as well as the coefficient of production or consumption of product $i$ in process $j a_{i, j}$ can be updated, if necessary. Possible scenarios were outlined throughout a period of $N T=20$ periods, in which each period corresponds to one year; that is, a total of 20 years.

Product demand estimates were based on the current chemical productions, imports and exports (ABIQUIM, 2012; Alice Web, 2014). It was arbitrarily defined that in years 6 and $13,(t=6$ and $t=13$, respectively), demands for all petrochemical products increased by random percentages between $10 \%$ and $30 \%$. Initial plant capacities $\left(Q T_{j, t}, t=0\right)$ were considered to be equal to the current plant capacities. Also, the supplies of the products $\left(S_{i, t}\right)$ were relaxed, considering that it is possible to diversify the suppliers.

The product purchase prices in year $1\left(p p_{i, t=1}\right)$ were equal to the current purchase prices (ABIQUIM, 2012). Furthermore, the purchase prices were increased by $2 \%$ per year throughout the period of 20 years. By adjusting for inflation, one can convert the investment costs presented by Rudd et al. (1981) into initial unit plant investment costs $\left(i c_{j, t=1}\right)$, which are then increased by $1 \%$ per year. The unit operational cost of a process $j$ at time $t\left(o c_{j, t}\right)$ was considered to be $3 \%$ of the corresponding unit plant investment cost $i c_{j, t}$. Process capacities are bounded by upper limits $\mathrm{Qmax}_{j}$ (which were based on data presented by Rudd et al. (1981)) and lower limits $Q_{\min }$ (which were defined as $50 \%$ of the upper limits). 
Table 1. Economic results obtained in each scenario.

\begin{tabular}{|c|c|c|c|c|c|c|}
\hline & Case I & Case II & Case III & Case IV & Case V & Case VI \\
\hline Number of selected processes & 47 & 37 & 37 & 50 & 47 & 48 \\
\hline $\begin{array}{l}\text { Total cost (objective function) } \\
\text { (billion USD) }\end{array}$ & 673.1 & 679.3 & 644.7 & 753.2 & 476.7 & 869.4 \\
\hline \multicolumn{7}{|l|}{ Total investment cost } \\
\hline \multicolumn{7}{|l|}{ (billion USD) } \\
\hline $\begin{array}{l}\text { Case I: Base Cas } \\
\text { Case II: With inv } \\
\text { Case III: Deman }\end{array}$ & $\begin{array}{l}\text { nt limit } \\
\text { r than base case }\end{array}$ & $\begin{array}{l}\text { Case } \\
\text { Case } \\
\text { Case }\end{array}$ & $\begin{array}{l}\text { emand high } \\
\text { rchase price } \\
\text { urchase pric }\end{array}$ & $\begin{array}{l}\text { base case } \\
\text { than base } \\
\text { er than bas }\end{array}$ & & \\
\hline
\end{tabular}

In the base case, which is the starting point for further analyses, current process capacities, product demands, and prices are included in the mathematical model described in Section 2. Other cases were derived from the base case and compared to it, as explained in Section 4. One of them included a constraint for investment in new plants (Imax), according to Equation (12). In the other cases, an evaluation of the effect of changes in chemical demands and purchase prices on the petrochemical industry was conducted.

$\sum_{t \in T} \sum_{j \in J} I C_{j, t} \leq \operatorname{Imax}$

\section{RESULTS AND DISCUSSION}

In all cases studied, the objective function $Z$ in Equation (1) was minimized with the CPLEX solver included in the optimization software GAMS, version 24.3.3 (Rosenthal, 2014), on an Intel Core $^{\mathrm{TM}}$ i5-4300U (1.9 GHz, 4.00 GB of RAM). For mixed-integer programming, the CPLEX makes use of a branch and cut algorithm, which solves a series of linear programming subproblems. For linear programming, the solver uses the dual simplex algorithm (GAMS Development Corporation, 2014). The base case optimization problem has 49802 variables, from which 5900 are discrete variables, and the average solution time of the six scenarios studied was 95.3 seconds, applying the default relative gap termination tolerance of 0.1 .
The base case (that is, the solution of the model defined in Section 2 with current demands and purchase prices) is compared to the case in which the total investment cost is limited to Imax, as in Equation (12). Imax is taken as $70 \%$ of the total investment cost predicted in the base case.

Also, the base case is compared to the cases in which demand and purchase prices varied, since it is important to assess the sensitivity of the costs of the petrochemical industry to favorable or unfavorable economic conditions. Long-term predictions about the petrochemical industry may become inaccurate, as economi\&12bnditions are dynamic and may present large and rapid fluctuations. Consequently, it is useful to consider different future scenarios in order to support the investment decision.

Table 1 presents the total cost of the petrochemical industry (objective function), the total investment cost, and the number of processes selected for investment in each scenario.

\subsection{Current demands and purchase prices, without and with investment limit (Cases I and II)}

In the base case, investment in new plants of 47 processes was recommended over a period of 20 years, according to Table 1 . In the scenario where total investment was limited to $70 \%$ of the investment related to the base case, investment in new plants of 37 processes was recommended. 
In the scenario with investment limit, the restriction of investment caused the total cost to increase, when compared to that of the base case. One can see that lower investment and operational costs are not related necessarily to a lower total cost of the entire Brazilian petrochemical industry, since a higher value of the objective function was obtained in this scenario. In the scenario with investment limit, the industry should buy more chemical and petrochemical products to be used as raw materials and to satisfy market demand, as some products would be discontinued.

\subsection{Sensitivity analysis of the petrochemical network: demand variation (Cases III and IV)}

The sensitivity of the petrochemical industry network total cost to variations in demand was evaluated in two situations. First, demands for all petrochemical products were $30 \%$ lower than the demands defined in the base case. Second, demands were $30 \%$ higher than those in the base case. All other model parameters are equal to those of the base case (and no investment constraints were imposed in these cases). The objective of such analysis is to predict the behavior of the petrochemical industry in different economic conditions.

The scenario with lower demands represents a pessimistic economic forecast. In this case, fewer processes were selected for investment, 37 processes, in comparison with the base case, 47 processes (Table 1). Nevertheless, in the scenario with higher demands, new investments were encouraged, so that the total investment cost was higher than that obtained in the base case and the total number of selected processes was 50 .

\subsection{Sensitivity analysis of the petrochemical network: purchase price variation (Cases V and VI)}

A consistent investment analysis must take into account the sensitivity of the petrochemical industry to the purchase prices of chemicals. First, the purchase prices were defined as $30 \%$ lower than the values adopted in the base case. Second, the purchase prices of the base case were increased by $30 \%$. In the case where purchase prices are lower, buying some of the chemicals to supply the market can be more advantageous than investing in new plants. Differently, a situation in which purchase prices are high can be more economically attractive to new investment. No investment limit was imposed in such scenarios.

As one can see in Table 1, the total investment costs were almost the same in both scenarios, whereas the total cost of the petrochemical industry in the scenario with higher purchase prices is considerably higher than the cost in the scenario with lower purchase prices.

\subsection{Comparison with the literature}

Among 295 chemical processes that comprise the model, only 26 processes were selected for new investment in the six cases studied. The results indicate that these 26 processes are the most consistent for investment assessment, considering the model presented in this work, the variables defined in item 3 and the six different scenarios studied (which in turn represent favorable or unfavorable economic conditions when compared to the base case).

Table 2 shows the processes that require a capacity expansion and in what year this expansion must take place. In Table 2, each symbol represents investment in new plants in a different situation. For example, a new unit to produce butadiene via dehydrogenation of $n$-butane is recommended in the case where demand is higher than that of the base case ( $\square$ ) in years 6 and 13. In the base case $(\bullet)$, in the case where purchase price is lower than that of the base case $(\boldsymbol{\Delta})$ and where purchase price is higher than that of base case $(0)$, investment is suggested in year 13 . In Table 2 , the 26 processes selected for new investment in the six cases studied are distinguished from others by gray cells.

The results presented in the previous sections can be compared to a previous economic analysis by Bain \& Company, Inc. and Gas Energy (2014) ordered by the Brazilian Development Bank (BNDES). As described earlier, Bain \& Company, Inc. and Gas Energy (2014) identified investment opportunities to increase the production of some products that could reduce the Brazil's deficit in the chemical sector based on projected market and analysis of financial information. Some of these products were also selected for investment by the mixed-integer multiperiod model presented in this work. 
Table 3. Selected processes over the period of 20 years.

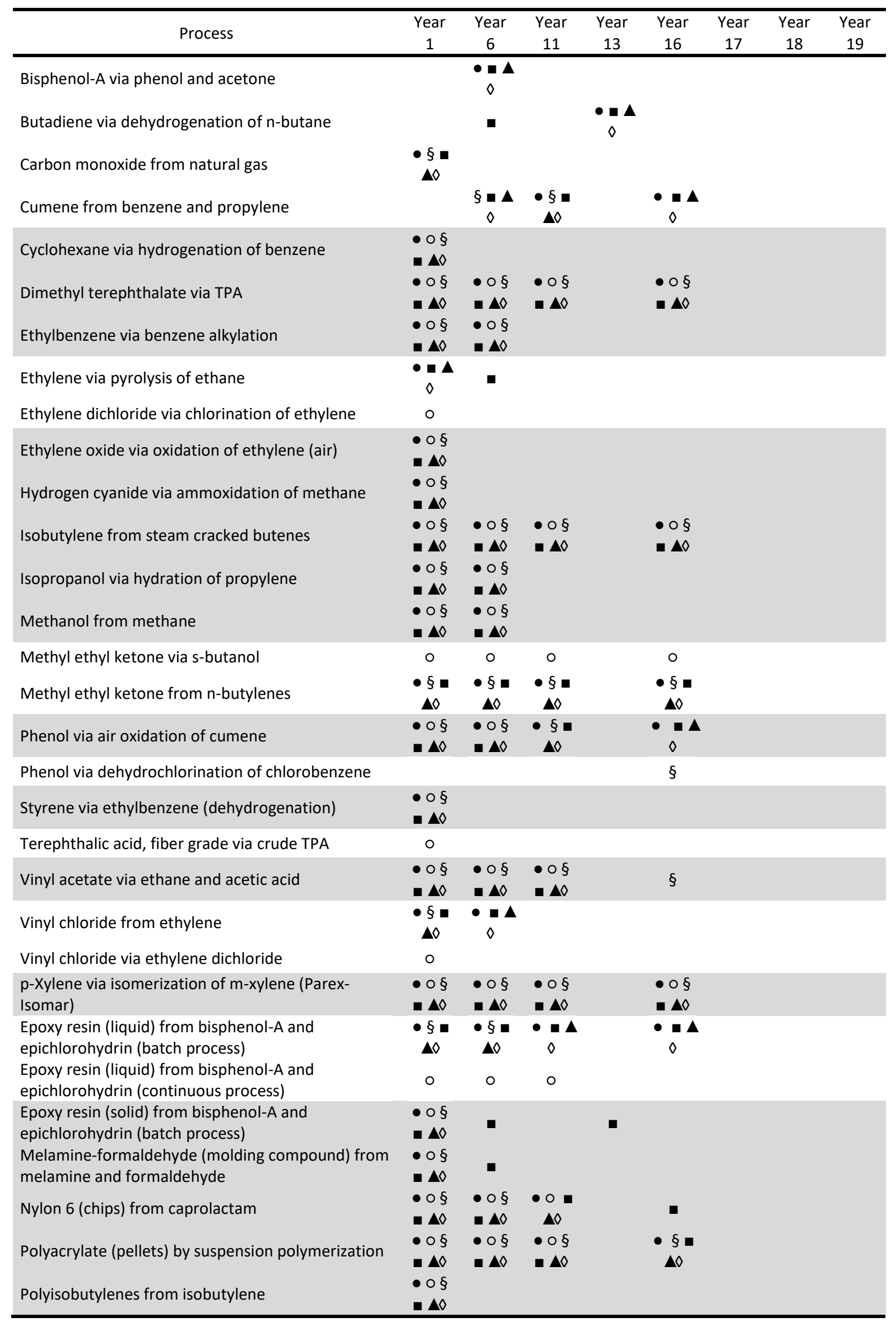


Table 2. Selected processes over the period of 20 years (continued).

\begin{tabular}{|c|c|c|c|c|c|c|c|c|}
\hline Process & $\begin{array}{c}\text { Year } \\
1\end{array}$ & $\begin{array}{c}\text { Year } \\
6\end{array}$ & $\begin{array}{c}\text { Year } \\
11\end{array}$ & $\begin{array}{c}\text { Year } \\
13\end{array}$ & $\begin{array}{c}\text { Year } \\
16\end{array}$ & $\begin{array}{c}\text { Year } \\
17\end{array}$ & $\begin{array}{c}\text { Year } \\
18\end{array}$ & $\begin{array}{c}\text { Year } \\
19\end{array}$ \\
\hline $\begin{array}{l}\text { Polybutylene terephthalate from DMT and 1,4- } \\
\text { butanediol }\end{array}$ & & & घ & & - § घ & & & \\
\hline Polycarbonate by continuous solution phosgenation & $\stackrel{\bullet \square}{\Delta \diamond}$ & $\underset{\Delta}{\bullet} \boldsymbol{\Delta}$ & घ & - $\Delta \Delta$ & घ & & & \\
\hline $\begin{array}{l}\text { Polyether polyol (glycerine-based triol) from } \\
\text { propylene oxide and glycerine }\end{array}$ & $\begin{array}{l}-\circ \S \\
\square \Delta\end{array}$ & $\begin{array}{l}-\circ \S \\
-\Delta \diamond\end{array}$ & ${ }_{\Delta 0}^{\circ}$ & & ${ }_{\Delta 0}^{0}$ & & & \\
\hline $\begin{array}{l}\text { Polyethylene (high-density) via Union Carbide } \\
\text { tecnology } \\
\text { Polyethylene (low density) from an autoclave } \\
\text { reactor (backmixed) }\end{array}$ & घ & a & घ & - $\Delta \triangleright$ & घ & & & \\
\hline Polyethylene glycol from ethylene oxide & $\begin{array}{l}-\circ \S \\
\square \diamond\end{array}$ & - ०§ & $\begin{array}{l}-\circ \S \\
\square \Delta \diamond\end{array}$ & & - $\S \square$ & & & \\
\hline $\begin{array}{l}\text { Polyethylene terephthalate (PET) from TPA and } \\
\text { ethylene glycol }\end{array}$ & $\begin{array}{c}\bullet \bullet \\
\Delta \diamond\end{array}$ & $\stackrel{0 \square}{\Delta \Delta}$ & $\begin{array}{c}\bullet \bullet \\
\Delta \circlearrowright\end{array}$ & & 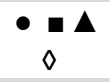 & & & \\
\hline $\begin{array}{l}\text { Polymethyl methacrylate (pellets) by batch bulk } \\
\text { polymerization }\end{array}$ & & & & & $\stackrel{\S \square}{\Delta \diamond}$ & & & o \\
\hline $\begin{array}{l}\text { Polypropylene by vapor phase process (BASF } \\
\text { technology) }\end{array}$ & & & & घ & & & घ & \\
\hline Polypropylene glycol from propylene oxide & & & & & & & 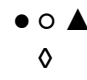 & \\
\hline Polystyrene (crystal grade) by bulk polymerization & & & - & & - & & & \\
\hline $\begin{array}{l}\text { Polystyrene (expandable beads) by suspension } \\
\text { polymerization }\end{array}$ & 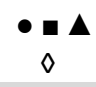 & 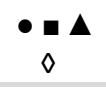 & घ & $\bullet \Delta \Delta$ & $\mathbf{\square}$ & & & \\
\hline $\begin{array}{l}\text { Polyurethane flexible foam (slab stock) from } \\
\text { polyether polyol and toluene diisocyanate }\end{array}$ & $\begin{array}{l}-\circ \S \\
\square \diamond\end{array}$ & $\stackrel{\S \square}{\Delta \nabla}$ & $\stackrel{\S \square}{\Delta \triangleright}$ & & $\stackrel{\S \square}{\Delta \diamond}$ & & & \\
\hline Polyvinyl alcohol from vinyl acetate & $\stackrel{\wp \square}{\Delta \diamond}$ & & & & & & & \\
\hline $\begin{array}{l}\text { Polyvinyl butyral by condensation of polyvinyl } \\
\text { alcohol with butyraldehyde } \\
\text { Polyvinyl chloride (general purpose) by liquid fase } \\
\text { bulk process }\end{array}$ & $\begin{array}{l}\circ \wp \\
\Delta \diamond \\
0 \square \\
\Delta ه\end{array}$ & ${ }_{\Delta 0}^{\circ}$ & $\begin{array}{c}-0 \square \\
\Delta \Delta\end{array}$ & $\S$ & $\boldsymbol{D}^{\bullet} \boldsymbol{\Delta}$ & & & \\
\hline SAN by suspension polymerization & $\begin{array}{c}\bullet \bullet \\
\Delta \diamond\end{array}$ & & & & & & & \\
\hline Urea-formaldehyde (molding compound) & - & $\mathbf{\square}$ & - & & $\mathbf{\square}$ & & & \\
\hline $\begin{array}{l}\text { Vinyl acetate/vinyl chloride copolymer by } \\
\text { suspension polymerization }\end{array}$ & & & & & & $=0$ & & \\
\hline $\begin{array}{l}\text { Vinylidene chloride/vinyl chloride copolymer by } \\
\text { suspension polymerization } \\
\text { Acrylic fibers from acrylonitrile and methyl } \\
\text { methacrylate (continuous solution polymerization) } \\
\text { Butyl rubber from isobutylene }\end{array}$ & $\begin{array}{l}\bullet \circ \S \\
\square \Delta\end{array}$ & ${ }_{\Delta \Delta}^{\circ}$ & घ & & & $\begin{array}{l}\text { - o } \\
\text { - } \Delta \triangleright \\
\text { - o } \\
-\Delta \diamond\end{array}$ & & \\
\hline EPDM rubber by suspension polymerization & & & & - & & & & \\
\hline Nitrile rubber by cold emulsion polymerization & & & & & & $\begin{array}{r}\circ \Delta \\
0\end{array}$ & & $\S$ \\
\hline Polybutadiene by lithium-catalyzed polymerization & $\bullet \boldsymbol{\Delta} \Delta$ & & & & & & & \\
\hline Polybutadiene by nickel- catalyzed polymerization & O & & & & & & & \\
\hline Polychloroprene (neoprene) via butadiene & & & & & & & - ०§ & \\
\hline SBR by cold emulsion polymerization & - & - & & $\bullet \boldsymbol{\Delta} \Delta$ & & & & \\
\hline SBR (latex) by hot emulsion polymerization & - & घ & & $\bullet \boldsymbol{\Delta} \Delta$ & & & & \\
\hline
\end{tabular}

-: Base Case

a: Demand higher than base case

o: With investment limit

$\Delta$ Purchase price lower than base case

$\S$ : Demand lower than base case

$\diamond$ : Purchase price higher than base case 
Bain \& Company, Inc. and Gas Energy (2014) indicated the installation of new process units for styrene-butadiene rubber (SBR) to meet exports and a future growth in domestic demand. It also recommended investment in plants for production of expandable polystyrene (EPS), which is currently imported to meet the local demand. Investment in SBR and expandable polystyrene plants was suggested by the mixed-integer multiperiod model solution in four scenarios, but not in the cases where there is investment limit and demands lower than those of the base case (Table 2). The model solution suggests that investment in SBR and expandable polystyrene units in less favorable economic conditions are not a priority. Moreover, investment in new styrene units is indicated by the model solution, since it is consumed in the production of EPS and SBR.

Likewise, Bain \& Company, Inc. and Gas Energy (2014) suggest that new butadiene rubber (BR), or polybutadiene, units should be built, since BR is currently imported to satisfy the local demand. Polybutadiene processes were selected for new investment in five scenarios studied in this work, but not in lower demand case.

Bain \& Company, Inc. and Gas Energy (2014) indicate an investment opportunity in polyurethanes units (and the intermediate products related to their production), as their imports supply $63 \%$ of the local demand. The authors highlighted the necessity for new polyether polyol, methylene diphenylene diisocyanate (MDI), and toluene diisocyanate (TDI) units, which are raw materials used in the polyurethane production. In the mixed-integer multiperiod model solution new polyurethane and polyether polyol units were selected in the six scenarios studied. Although TDI is a raw material for polyurethanes, the model solution did not predict new TDI units, which is bought in the six scenarios. That is, given the conditions adopted in this work, it is more advantageous to buy TDI instead of investing in new process units.

The Brazilian local demand for carbon fibers is supplied totally by imports. Currently, the main route for carbon fiber production uses polyacrylonitrile (PAN) and, although producing acrylonitrile, Brazil does not produce PAN. Bain \& Company, Inc. and Gas Energy (2014) suggested the investment in a new carbon fiber unit which uses imported PAN at first, for a positive impact on the commercial balance. Afterwards, a new process unit for PAN production should be built. The use of PAN in carbon fibers production was not directly considered in the mixed-integer multiperiod model proposed. However, the model solution suggested new investments in units for the general group of acrylic fibers from acrylonitrile and methyl methacrylate (which includes PAN) in the six scenarios studied (Table 2).

Another product segment studied by Bain \& Company, Inc. and Gas Energy (2014) is the one comprised of special polyamides or nylon (name created by DuPont). Special polyamides (such as PA6,10; PA11 and PA12 - or nylon 6,10; nylon 11 and nylon 12) are more chemically resistant and absorb less water than the traditional ones (such as PA6 and PA6,6 - or nylon 6 and nylon 6,6). Bain \& Company, Inc. and Gas Energy (2014) state that an increase in the production of special polyamides would result in a positive impact on the commercial balance. The construction of new PA6 units to replace imports is also suggested in this report. Special polyamides were not considered in this work, but new PA6 process units were suggested by the model solution in the six scenarios, showing that replacing the PA6 imports by the local production can be attractive economically.

According to Bain \& Company, Inc. and Gas Energy (2014), imports meet $83 \%$ of local demand for high-tenacity polyester (polyethylene terephtalate, PET). This is the reason why the authors recommended the expansion of the domestic production of high-tenacity PET. The production processes of high-tenacity PET and commodity-grade PET use the same raw materials and the industrial polymer plants usually are the same for both processes. Although the hightenacity polyester does not differ from commoditygrade PET in this work, the PET production process was selected for investment in five of the six scenarios studied. The case with a demand lower than that of the base case was the only one in which new PET units were not predicted.

Though the model solution and the analysis by Bain \& Company, Inc. and Gas Energy (2014) are only roughly comparable, they determine similar directions to the Brazilian petrochemical industry. For instance, polymers such as polyethylene (PE), 
polypropylene (PP), and polyvinyl chloride (PVC) were outside the scope of the report by Bain \& Company, Inc. and Gas Energy (2014), which focuses on the main products that potentially influence the commercial balance. Nevertheless, the model solution suggests investment in new process units for PE in four scenarios studied, and for PVC in the six scenarios studied (Table 2).

\section{CONCLUSIONS}

The mixed-integer multiperiod model presented in this work is useful for the long-range planning for the Brazilian petrochemical industry. In the six future scenarios defined (the base case, the case with an investment constraint, the cases with lower and higher demands and the cases with lower and higher purchase prices) 26 chemical processes were selected for investment. The model solution suggests that processes for products such as polyurethane, polyether polyol, acrylic fibers and polyamide-6 (nylon 6) should have their capacities increased so that the cost function attains its minimum. Investment in such processes is also mentioned in a report by Bain \& Company, Inc. and Gas Energy (2014), which identified opportunities for the diversification of the Brazilian chemical industry. This report presents opportunity analyses based on economic data and chemical industry sector growth projections. Despite being based on different premises, this work indicates similar directions for investment in new process units. It is expected that a model with more precise data yields a more realistic investment analysis (since most of the process and costs data are unavailable, they are based on the values given by Rudd et al. (1981) and have been updated for the current situation of Brazil). Also, the investment analysis can be expanded by including in the model different products and new technologies.

In conclusion, this mixer-integer multiperiod model of the Brazilian petrochemical industry is suitable for a consistent investment assessment in different scenarios. The model may support efficiently business decisions about investments, adoption of new technologies, and market variations.

\section{NOTE}

Any opinions, findings, conclusions, or recommendations expressed in this material are those of the authors and do not reflect the views of Petróleo Brasileiro S.A. (PETROBRAS) or are part of its Business and Management Plan.

\section{NOMENCLATURE}

Parameters:

$a_{i, j}$ : coefficient of production or consumption of product $i$ on process $j$

$D_{i, t}$ : demand of product $i$ in time $t$, ton/year

$i$ : chemical product

$i c_{j, t}$ : unitary investment cost of process $j$ in time $t$, USD/ton

Imax: investment cost upper limit, USD

$j:$ chemical process

NC: number of chemical products

NP: number of chemical processes

NT: number of periods

$o c_{j, t}$ : unitary operational costs of process $j$ in time $t$, USD/ton

$p c_{i, j}$ : process parameter of product $i$ in process $j$

$p p_{i, t}:$ purchase price of product $i$ in time $t, \mathrm{USD} /$ ton

Qmax $j$ : upper capacity limit of process $j$, ton/year

$Q \min _{j}$ : lower capacity limit of process $j$, ton/year

$S_{i, t}$ : supply of product $i$ in time $t$, ton/year

$t$ : period

Binary variables:

$y_{j, t}$ : decision of investment on process $j$ in time $t$

Continuous variables:

$I C_{j, t}:$ investment cost of process $j$ in time $t$, USD/year

$O C_{j, t}$ : operational costs of process $j$ in time $t$, USD/year

$P_{i, t}:$ purchase of product $i$ in time $t$, ton/year

ProcCont $i, t$ : control of the processes that produce product $i$ in time $t$

ProdCont $i, t$ : control of the investment on a new process to produce product $i$ in time $t$ 
$Q_{j, t}$ : new capacity of process $j$ in time $t$, ton/year

$Q T_{j, t}$ total capacity of process $j$ in time $t$, ton/year

$Q T_{j, t-1}$ : total capacity of process $j$ in time $t-1$, ton/year

Z: total cost over all time period (objective function), USD

Symbols:

- : base case scenario

0 : scenario with investment limit

$\S$ : scenario with demand lower than base case

- : scenario with demand higher than base case

$\Delta$ : scenario with purchase price lower than base case

$\diamond$ : scenario with purchase price higher than base case

\section{REFERENCES}

$A B I Q U I M$, Anuário da indústria química Brasileira. ABIQUIM- Associação Brasileira da Indústria Química, São Paulo, 2012. (in Portuguese).

Al-Fadli, A.M., Soliman, M.A., Wagialla, K.M., AlMutaz, I.S., A network model for the optimal planning of the Saudi petrochemical industry. Journal of King Saud University - Engineering Sciences, v. 14, no. 2, p. $295-309,1988$.

Alice Web. Sistema de análise das informações de comércio exterior (Alice Web). Available at: http://aliceweb.mdic.gov.br. Accessed on 13 June 2014. (in Portuguese).

Al-Sharrah, G.K., Hankinson, G., Elkamel, A., Decision-making for petrochemical planning using multiobjective and strategic tools. Chemical Engineering Research and Design, v. 84, no. 11, p. 1019 - 1030, 2006. https://doi.org/10.1205/cherd.05198

Al-Sharrah, G.K., Alatiqi, I., Elkamel, A., Modeling and identification of economic disturbances in the planning of the petrochemical industry. Industrial \& Engineering Chemistry Research., 42, p. 4678-4688, 2003. https://doi.org/10.1021/ie021008f
Al-Sharrah, G.K., Alatiqi, I., Elkamel, A., Planning an integrated petrochemical business portifolio for long-range financial stability. Industrial \& Engineering Chemistry Research, 41, p. 27982804, 2002. https://doi.org/10.1021/ie0106635

Al-Sharrah, G.K., Alatiqi, I., Elkamel, A., Alper E., Planning an integrated petrochemical industry with an environmental objective. Industrial \& Engineering Chemistry Research, 40, p. 21032111, 2001. https://doi.org/10.1021/ie0007466

Bain \& Company, Inc., Gas Energy. Study of the potential for diversification of the Brazilian chemical industry: final report. Bain \& Company, Inc., São Paulo, 2014.

Jiménez, A.; Rudd, D.F.; Meyer, R.R., A study of the development of a Mexican petrochemical industry using mixed-integer programming. Computers \& Chemical Engineering, v. 6, no. 3, p. $219-229,1982$.

https://doi.org/10.1016/0098-1354(82)80013-6

GAMS Development Corporation. GAMS - The Solver Manuals. GAMS Development Corporation, Washington, 836p, 2014.

Loução Jr., F.L., Avaliação da indústria petroquímica no Brasil: desenvolvimento de modelo via programação matemática. $x, 112 \mathrm{p}$. Dissertação de Mestrado. Programa de PósGraduação em Tecnologia de Processos Químicos e Bioquímicos, UFRJ, Rio de Janeiro, 2016. (in Portuguese).

Rosenthal, R. E. GAMS - A User's Guide. Tutorial by Richard E. Rosenthal. GAMS Development Corporation, Washington, 12, 308p, 2014.

Rudd, D.F., Fathi-Afshar, S., Trevino, A.A., Stadtherr, M.A., Petrochemical technology assessment. John Willey \& Sons, New York, 370p, 1981.

Toledo, C.E.E.; Aranda, C.G.; Mareschal, B., Petrochemical industry: assessment and planning using multicriteria decision aid methods. Technology and Investment, v. 1, no.2, p. 118 134, 2010. https://doi.org/10.4236/ti.2010.12015 